\title{
Study on Emergency Drug Inventory Models based on Internet+
}

\author{
Zhumin chen $^{1, a}$,Xiaoyu Li ${ }^{2, b}$ \\ ${ }^{1}$ Shanghai Second Polytechnic University, Shanghai,201620,China \\ ${ }^{2}$ Shanghai Jiaotong University Affiliated First People's Hospital, Shanghai,201209,China \\ aemail:chenzhumin@sspu.edu.cn, ${ }^{\mathrm{b} e m a i l}:$ lixiaoyulxb@sina.com
}

Keywords: Internet+ ;Emergency; Drug; Inventory

\begin{abstract}
Emergency drug inventory is a key problem for emergencymanagement.Inthis study, an emergency drug inventory model is proposed, which is based on Internet. A genetic algorithm is developed to obtain the optimal solution of the proposed model. An example is included to illustrate the result of the model.
\end{abstract}

\section{Introduction}

In the progress of science and technology, medical level is also increasing. There are many nature disastershave been happened in recent years, which have caused great harms to people's life and wealth. So it is urgent to establish an emergency drug reserve system. We should also consider the special nature and waste of emergency drug.

SantosoWibowo and HepuDeng[1] presented multicriteria analysis for evaluating and selecting Suppliers under uncertainty. Jiuh-BilingSheu[2] included the core framework of emergency logistics.Byung Do Chung [3] studies the distributional robust chance-constrained approach based on dynamic traffic assignment under uncertainty.

YumeiBao and Guixiang[4] Chen proposed the problem and corresponding strategies in emergency preserve. Zijun[5] Wang discussed the mechanism of emergency material reserve. LinduZhao[6][7] presented the emergency network construction based on crisis resource management.Longfei Wang[8] proposes a time-space network model to address the emergency logistics planning problem.

Save lives is the most important, so the hospital must do the preparation of emergency drug reservation in the emergency event. This paper presents the models to minimize the cost of emergency drug while satisfy the sum demand.

\section{Notations and assumptions}

To establish the mathematical model, the following notations and assumptions are used.

\section{Notations}

T time of supply

$\mathrm{N}$ vendor's number

M hospital's number

U demand for U unit emergency drug

$Y$ hospital reserve quota

$\mathrm{Q}_{\mathrm{k}}$ the maximum supply of vendor $\mathrm{k}$

$\mathrm{C}_{\mathrm{y}}$ the storage cost of hospital y

$\mathrm{C}_{\mathrm{ky}}$ the cost per unit of transportation

$t_{k y}$ the time of transportation

$\mathrm{C}$ the sum of cost

$\mathrm{N}_{\mathrm{ki}}$ the amount of vendors

$\mathrm{N}_{\mathrm{i}}$ the amount of vendors whose supply time is smaller than $\mathrm{T}$

a the expand scale of $\mathrm{T}$

$\mathrm{N}_{\mathrm{ai}}$ the sum of vendors whose supply time is not greater than $\mathrm{a} \times \mathrm{T}$ 


\section{Assumptions}

The adopted assumptions are as follows:

1. In time $\mathrm{T}, \mathrm{N}$ vendors supply emergency drug to $\mathrm{M}$ hospitals.

2. thevendors'vehicles all can satisfy the demand for transportation, each vehicle can carry W unit drug

\section{Cooperative Reserve Model}

The model of emergency drug reserve is based on Internet+. It is a cooperative reserve model, which satisfies the amount demand and reduces the cost of reservation. There are two subsystems in this model. One is composed of hospitals; the other is composed of drug suppliers. This system is optimized based on Internet, which can get the lowest cost of storage and supply drug. The model is depicted in Figure 1. This model is composed of cooperative center and the collective drug suppliers and several hospitals. The cooperative center is in charge of information collection and command send.

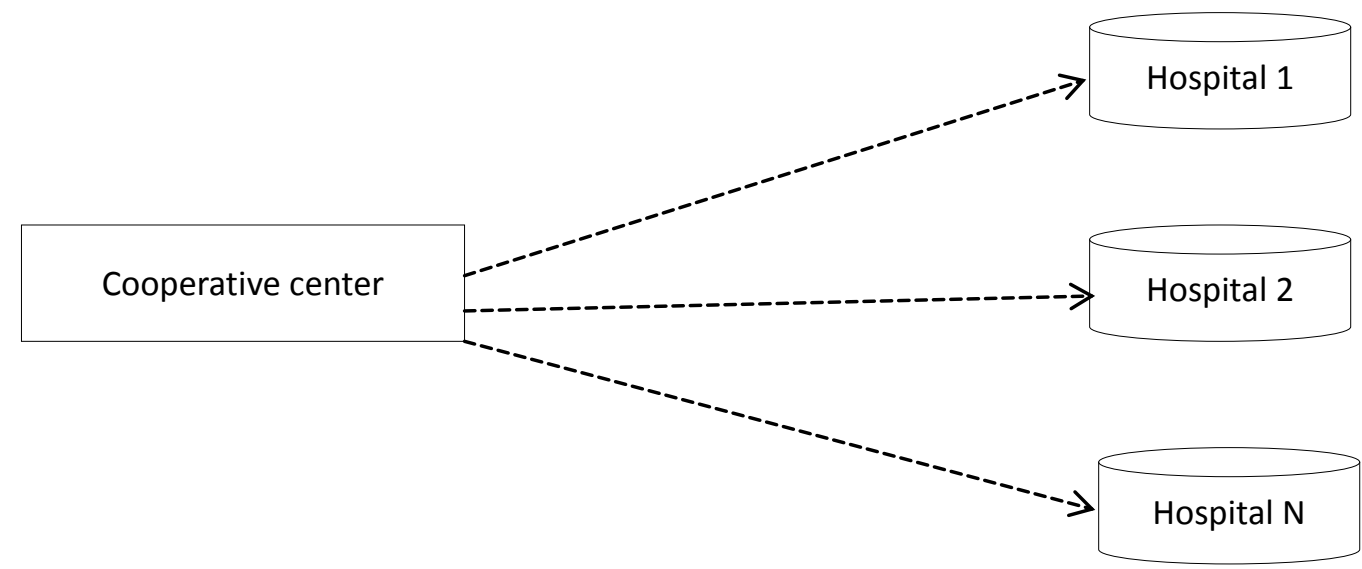

Information flow

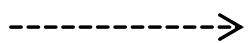

Problem description

(1) Pick up the drug suppliers which can be satisfied with supply time, when the sum of maximum supply is greater or equal to demand for hospitals then it can be optimized.

(2) When the sum of maximum supply is smaller than demand for hospitals, the cooperative center will expand a scale of supply time, the optimize the new suppliers.

(3) If the maximum supply is still smaller than demand for hospitals after expanding a scale of supply time, then we should adopt some incentive measures to increase the supply volume.

The proposed model

The objective function can be described as follows. 


$$
\begin{aligned}
& \left.\min C=\delta_{1}\left(\sum_{k=1}^{N_{i}} Q_{k}-U\right) \times\left(\sum_{y=1}^{M} \sum_{k=1}^{N_{i}} \operatorname{int}\left(\frac{Q_{k y}}{w}\right)+\delta\left(\frac{Q_{k y}}{w}\right)\right) \times C_{k y}\right)+ \\
& \left.\delta_{1}\left(U-\sum_{k=1}^{N_{i}} Q_{k}\right) \times \delta_{1}\left(\sum_{k=1}^{N_{a i}} Q_{k}-U\right) \times\left(\sum_{y=1}^{M} \sum_{k=1}^{N_{a i}} Q_{k y} \times C_{y}+\sum_{y=1}^{M} \sum_{k=1}^{N_{a i}} \operatorname{int}\left(\frac{Q_{k y}}{w}\right)+\delta\left(\frac{Q_{k y}}{w}\right)\right) \times C_{k y}\right) \\
& \mathrm{k}=1,2, \ldots, \mathrm{N}, \mathrm{y}=1,2, \ldots ., \mathrm{M}, \\
& \text { s. t. } \sum_{k=1}^{N_{k i}} Q_{k y}=Z_{y}, \sum_{y=1}^{M} Q_{k y} \leq Q_{k}, \sum_{y=1}^{M} Z_{y}=U ; \delta(x)=\left\{\begin{array}{cc}
1 & x \text { is not integer } \\
0 & x \text { is integer }
\end{array}\right. \\
& \delta_{1}(x)=\left\{\begin{array}{l}
1 \text { while } x>0 \\
0 \text { while } x \leq 0
\end{array}\right.
\end{aligned}
$$

\section{The solving method}

Step1: accordingt $t_{k} \leq T$, determine the set of suppliers and the element number $\mathrm{N}_{\mathrm{i}}$;

Step2: $G=\sum_{k=1}^{N_{i}} Q_{k}-U$, count the value of $G$ and judge the process of algorithm according to to $\mathrm{G}$;

(1) if $G \geq 0$,determine the set of suppliers, jump to step6;

(2) if $G<0$, then jump to step 3;

step 3: input the expand scale of time a ,determine the set of suppliers and element number $\mathrm{N}_{\mathrm{ai}}$ which satisfy the condition of $t_{k} \leq \mathrm{a} \times \mathrm{T}$, then jump to step 4;

step 4: set $G_{1}=\sum_{k=1}^{N_{a i}} Q_{k}-U$, count the value of $G_{1}$, then judge the process of algorithm according to the result.

(1) if $G_{1} \geq 0$, determine the set of suppliers who satisfy the condition of $t_{k} \leq a \times T$, then jump to step 6;

(2) if $\mathrm{G}_{1}<0$, jump to step 5;

step 5: According to the actual situation, we will adopt some incentive measures to increase the supply volume.

Step 6: adopt genetic algorithm, count the sum of cost which satisfy the minus sum cost of storage and transportation, then jump to step 7;

Step 7: done.

The genetic algorithm as follows:

1.Initial Population

$\mathrm{T}$ chromosomes POP1..POPSIZE $=\left(\mathrm{Q}_{1 \mathrm{~T}}, \mathrm{Q}_{2 \mathrm{~T}}, \ldots, \mathrm{Q}_{\mathrm{LT}}\right)$ are randomly generated by random integer, which satisfy $\sum_{\mathrm{k}=1}^{\mathrm{L}} \mathrm{Q}_{\mathrm{kt}}=\mathrm{M}$, according constraint condition ,determine the feasible region $\mathrm{Q}_{\mathrm{kt}} \in\left[0, \mathrm{Q}_{\mathrm{k}}\right], \sum_{\mathrm{k}=1}^{\mathrm{L}} \mathrm{Q}_{\mathrm{kt}}=\mathrm{M}$, the generation of generator as follows:

The first generator $: Q_{1 T} \in\left[0, \min \left(Q_{1}, M\right)\right]$;

The second generator: $Q_{2 T} \in\left[0, \min \left(Q_{1}, M-Q_{1 T}\right)\right]$;

......

The L-1 generator: $\mathrm{Q}_{\mathrm{L}-1 \mathrm{~T}} \in\left[0, \min \left(\mathrm{Q}_{\mathrm{L}-1}, \mathrm{~A}_{\mathrm{L}-1 \mathrm{~T}}, \mathrm{M}-\sum_{\mathrm{k}=1}^{\mathrm{L}-2} \mathrm{Q}_{\mathrm{kT}}\right)\right]$;

The L generator: $\mathrm{Q}_{\mathrm{LT}=\sum_{\mathrm{k}=1}^{\mathrm{L}-1} \mathrm{Q}_{\mathrm{kT}}}$

\section{Fitness Function}

The fitness function is by definition the measure of how well a candidate solution solves the problem. It is important to distinguish between fitness function and objective function that are used in genetic algorithms. The fitness function, which may be defined as the sum of all objective function value and the penalty for constraint violation, ban be calculated for each chromosome. Where $\mathrm{f}=\mathrm{C}$.

\section{Selection}

The selection process follows the evaluation of the fitness function. Fitness proportionate 
selection is also known as roulette wheel selection. The selection is a procedure in which chromosomes are selected POPSIZE times for reproduction.

\section{Crossover}

Crossover is a recombination technique used for creation of one or more offspring form the parents selected by means of exchange of the genetic material. According the rate $\mathrm{P}_{c}$, determine the sum of crossover $n=$ POPSIZE $\times P_{c}$ until the crossover number is $n$.

5.Mutation

Mutation is an operator that allows reappearing of the genetic material, that otherwise might be lost from the population using crossover alone. Mutation is a mechanism that ensures the algorithm is not stuck in local minima. The number of mutations is determined by choice and is often not more than several percepts from the number of variables in the population:

$\mathrm{nn}=$ POPSIZE $\times \mathrm{P}_{\mathrm{m}}$, where $\mathrm{P}_{\mathrm{m}}$ is the mutation rate.

\section{Example and discussion}

According to the CDC forecast there will be 4 hospitals demand for 100 unit emergency drug. There are 5 suppliers, the information of hospital as Table 1, the suppliers and hospital as Table 2 or Table 3.

Table 1 Hospital Table

\begin{tabular}{|c|l|l|l|l|}
\hline Hospital & A & B & C & D \\
\hline $\mathrm{Q}_{\mathrm{k}}$ & 30 & 34 & 28 & 30 \\
\hline $\mathrm{C}_{\mathrm{k}}$ & 20 & 30 & 40 & 30 \\
\hline
\end{tabular}

Table 2 Supply Time of vendors

\begin{tabular}{|c|c|c|c|c|c|}
\hline $\begin{array}{c}\text { Supplier } \\
\text { Hosplital }\end{array}$ & a & b & c & d & e \\
\hline A & 4 & 2 & 4 & 5 & 6 \\
\hline B & 5 & 3 & 3 & 4 & 3 \\
\hline C & 3 & 4 & 3 & 7 & 2 \\
\hline D & 5 & 6 & 5 & 2 & 4 \\
\hline
\end{tabular}

Table3 Transportation price of vendors

\begin{tabular}{|c|c|c|c|c|c|}
\hline $\begin{array}{c}\text { Supplier } \\
\text { Hospital }\end{array}$ & a & b & c & d & e \\
\hline A & 300 & 200 & 300 & 450 & 600 \\
\hline B & 400 & 200 & 400 & 350 & 400 \\
\hline C & 300 & 350 & 400 & 550 & 300 \\
\hline D & 400 & 400 & 260 & 300 & 200 \\
\hline $\begin{array}{c}\text { Maxium } \\
\text { supply }\end{array}$ & 17 & 15 & 18 & 8 & 9 \\
\hline
\end{tabular}

To minimize the transportation and storage cost, the amount of each vendor supply for hospital should be got from the cooperative model. From data, it can be included that the supply capacity of vendors is greater than the sum demand of hospital, so we can optimize by genetic algorithm, the optimize result as Table 4.

Table 4 Optimize result

\begin{tabular}{|l|l|l|l|l|l|l|}
\hline $\begin{array}{c}\text { Supplier } \\
\text { Hospitak }\end{array}$ & A & B & C & D & E & $\begin{array}{l}\text { Planned } \\
\text { reserves }\end{array}$ \\
\hline A & 17 & 8 & 5 & 0 & 0 & 30 \\
\hline B & 0 & 7 & 0 & 0 & 0 & 7 \\
\hline C & 0 & 0 & 0 & 0 & 0 & 0 \\
\hline D & 0 & 0 & 13 & 8 & 9 & 30 \\
\hline Total cost & 18890 &
\end{tabular}

The parameters in genetic algorithm, POPSIZE $=50, \mathrm{P}_{c}=0.3, \mathrm{P}_{\mathrm{m}}=0.1$.It is no difficult to verify 
that the total cost is smaller than any scheme without optimization.

In this study, a cooperative model based on Internet is proposed. The quantity of reserves is optimized by using the mathematical model. It satisfies the economy and emergency in drug reserve.

\section{References}

[1]SantosoWibowo, Hepu Deng. Multicriteria Analysis for Evaluating and selecting Suppliers under Uncertainty [J]. Proceeding of 2011 3rd IEEE international Conference on Management and Engineering.2011,4:28-32

[2]Jiuh-BilingSheu. Special Issue on Emergency Logistics Management Transportation Research Part E: Logistics and Transportation Review[J]. Transportation Research Part E, 2005,41:459-460

[3]Byung Do Chung. Tao Yao. Bo Zhang.Dynamic traffic assignment under uncertainty: a distributional robust chance-constrained approach[J].Netw Spat.Econ.2012,12(1):167-181

[4]YumeiBao. Study on emergency storage policy[J]. Science \& Technology Information, 2008(34):67-69

[5]ZijunWang.Study on establishing mechanism of material storage for treat with pubichealth.Chinese Journal of Public Health Management.2004,20(6):502-503

[6]LinduZhao.Urban safety emergency network based on crisis resource management[J].Journal of Southeast University.2004,6(4):48-51

[7]LinduZhao.A research on emergency logistics network of urban major hazards[J]. Journal of Southeast University.2007,9(1):27-29

[8]Longfei Wang, Jie Song, Leyuan Shi [J]. Optimization Letters 2015(9):1533-1552 